\title{
Effect of exogenous glucocorticoids on male hypogonadism
}

\author{
ADEL GASSAB MOHAMMED ${ }^{1}$, ABBAS ALI MANSOUR $^{2}$ and JAWAD HASSAN AHMED ${ }^{2}$ \\ ${ }^{1}$ Thi-Qar Specialized Diabetes, Endocrine and Metabolism Center, Endocrine and Metabolism Division, Department of \\ Medicine, College of Medicine, University of Thi-Qar, Nasiriyah, Thi-Qar 64001; \\ ${ }^{2}$ Faiha Specialized Diabetes, Endocrine and Metabolism Center, Endocrine and Metabolism Division, \\ Department of Pharmacology, College of Medicine, University of Basrah, Basrah 61013, Iraq
}

Received January 22, 2020; Accepted April 6, 2020

DOI: $10.3892 /$ br.2020.1319

\begin{abstract}
The aim of the present study was to investigate the effects of exogenous glucocorticoids (GCs), a potent cause of male hypogonadism, on the function of the hypothalamicpituitary-gonadal axis, and to determine their secondary effects in male patients. The present study was a case-controlled study conducted in Basrah, Iraq. Of the 152 participants who met the inclusion criteria, 100 patients used different types of GCs. Of these 100 patients, 57 patients $(57 \%)$ were current GC users, and 43 patients $(43 \%)$ were not currently using GCs (had not used GCs in the past 30 days). The control group was comprised of 52 men (34.21\%), considered as healthy participants, although 7 men (13.65\%) were biochemically diagnosed with hypogonadism. Current GC exposure significantly decreased the total and free testosterone levels, whereas previous GC exposure increased estradiol (E2) levels, with the 31 patients on oral dexamethasone (cumulative dose, $18.9 \mathrm{mg}$ ) exhibiting a 7.5-fold increased risk of being diagnosed with hypogonadism. For previous GC users, a significant increase in the E2 level was observed, whereas all other gonadal hormonal levels were within normal reference ranges, including the total and free testosterone levels. The total cumulative dose of equivalent GCs was $240 \mathrm{mg}$, which resulted in a decrease in total testosterone levels, and subsequent hypogonadism. Oral dexamethasone at a lower total cumulative dose resulted in hypogonadism.
\end{abstract}

\section{Introduction}

Male hypogonadism is a clinical syndrome in which the diagnosis is dependent on hypogonadal signs or symptoms

Correspondence to: $\mathrm{Dr}$ Adel Gassab Mohammed, Thi-Qar Specialized Diabetes, Endocrine and Metabolism Center, Endocrine and Metabolism Division, Department of Medicine, College of Medicine, University of Thi-Qar, AlMostafawia Street, Nasiriyah, Thi-Qar 64001, Iraq

E-mail: adel.gassab@fdemc.iq

Key words: glucocorticoids, glucocorticoid abuse, gonadal hormones, hypothalamic-pituitary-gonadal axis, male hypogonadism, testosterone and unequivocally low serum testosterone (T) levels (1). $\mathrm{T}$ replacement therapy can correct sexual dysfunction, restore libido, increase lean body mass and reduce fat mass, and increase bone mineral density and vitality (2). The term primary hypogonadism refers to testicular disorders, which are characterized by low serum $\mathrm{T}$ levels despite high follicle-stimulating hormone (FSH) and luteinizing hormone (LH) levels. The causes of primary hypogonadism include the following: i) Genetic conditions (such as Klinefelter syndrome and gonadal dysgenesis), ii) anatomical defects, iii) infection, iv) tumors, v) injuries, and vi) iatrogenic causes such as surgery or certain drugs, including glucocorticoids (GCs) (3).

The term secondary hypogonadotropic hypogonadism refers to the insufficient release of gonadotropin-releasing hormone $(\mathrm{GnRH})$ with low to normal FSH, LH and T levels. The causes of secondary hypogonadism include the following: i) Hyperprolactinemia (often secondary to pituitary adenoma), ii) GnRH deficiency with anosmia (Kallmann syndrome), iii) hypothalamic lesions or disorders, and iv) pituitary lesions or disorders (4). The term normogonadotropic hypogonadism refers to the symptoms or signs of hypogonadism accompanied with low serum $\mathrm{T}$ and normal LH levels (5).

Hypogonadism has several symptoms, including sexual dysfunction, lethargy, depressed mood, poor concentration and memory, mild anemia, and a diminished sense of well-being (5). The most common features of hypogonadism in adulthood that suggest androgen deficiency are decreased libido, impotence, and oligo- or azoospermia. Other symptoms may include fatigue, loss of bone and muscle mass, and increased fat mass and related metabolic disorders, in addition to impairment of cognitive function. Some elderly men may develop a mild $\mathrm{T}$ deficiency and present with symptoms suggestive of hypogonadism in young men (6).

GC abuse is another cause of male hypogonadism (7). GCs are classified as short-acting, intermediate-acting or long-acting (Table I) based on the duration of adrenocorticotropic hormone (ACTH) suppression and the relative GCs and mineralocorticoids effects (a group of hormones, including aldosterone, which regulate the balance of water and electrolytes in the body) (8).

Exogenous GC causes an acute reduction in $\mathrm{T}$ levels in men by directly suppressing gonadal steroid secretion; thus, GC therapy frequently and significantly decreases the serum $\mathrm{T}$ levels. Furthermore, this effect appears to be 
mediated by the suppression of GnRH secretion by the hypothalamus $(9,10)$.

The decrease in the total T (TT) and free T (FT) levels in men who use GCs may be attributed to GC binding to $\mathrm{GC}$ receptors located in several tissues and organs in the body, such as the Leydig cells, decreasing $\mathrm{T}$ biosynthesis via $11 \beta$-HSD1 reductase activity (11). Leydig cell apoptosis is another mechanism attributed to decreased $\mathrm{T}$ levels (12).

The aim of the present study was to investigate the effects of exogenous GC use, considered a potent cause of male hypogonadism, on the function of the hypothalamic-pituitary-gonadal (HPG) axis, and to determine any secondary effects in male patients.

\section{Materials and methods}

Patients. The present study was approved by the Faiha Specialized Diabetes, Endocrine and Metabolism Center. Each participant provided written informed consent. Before providing consent, patients were provided with a sufficient explanation to ensure that each patient clearly understood the nature of the study.

The present study was a case-controlled study performed at Faiha Specialized Diabetes, Endocrine and Metabolism Center (FDEMC) in Basrah, Iraq. The study was performed between June 2017 and June 2018. All participants were admitted to FDEMC due to an endocrine disorder. In addition to clinical examination, age and medical history (for example, smoking history) were obtained as shown in Table II.

Using prepared study questionnaires, patients were asked about the following: i) Type of steroid used (oral/parenteral/depot injections); ii) method of use (prescription/nonprescription); iii) estimated total equivalent cumulative dose; and iv) current or previous GC use.

The inclusion criteria were adult males aged 18-55 years who were currently using or at any time in the previous year used GCs at a dose of $7.5 \mathrm{mg}$ prednisolone or equivalent for at least 10 days, regardless of their symptoms or causes of referral; based on the criteria used by Crawford et al (13). Previous GC users were stopping GC in the last 30 days and less than this period which mean current users (14).

The exclusion criteria were any patients with at least one of the following: History of orchitis; undescended testis (unilateral or bilateral) and unilateral or bilateral testicular volume $<4 \mathrm{ml}$; established atherosclerosis or cardiovascular disease; concomitant use of known erectile dysfunction-induced medications (such as antidepressants or opioids); history of spine injury; patients who had previously undergone prostate surgery; history of radiation therapy to the pelvic area; patients who had previously undergone surgery to the external genitalia and patients with an acute illness for the past month; history of critical illness requiring intensive care unit or coronary care unit admission in the past 3 months (15); any head injury or trauma in the past year (16); pituitary adenoma or history of hypopituitarism; underlying diseases [for example, asthma, chronic obstructive pulmonary disease, osteoarthritis, rheumatoid arthritis (RA)]; or use of any anabolic steroid.

Of the 187 participants enrolled in the present study, 35 were excluded and 100 used different types of GC (median age, 37 years; range 17-50 years). Of the GC users, 57 patients
(57\%) were current GC users (median age, 37 years; range 17-50 years), and 43 patients (43\%) were not currently using GCs (median age, 36 years; range 17-49 years). The control group was comprised of 52 participants (34.21\%) who were considered healthy (median age, 38 years; range 19-49 years), with 7 participants $(13.65 \%)$ being biochemically diagnosed with hypogonadism.

Physical evaluation. Body hair thickness, presence of gynecomastia, testicular volume, pubic and axillary hair assessment, and wrinkling around the face were physically examined to assess the presence of hypogonadism. Signs of steroid use including moon face, buffalo hump, supraclavicular fat pad, thin skin, abdominal obesity, striae, proximal muscle weakness, bruises and petechiae were assessed. Furthermore, a thorough physical examination was performed.

Anthropometric analysis including body weight and height measurements was performed with the patient wearing light clothes and no shoes, using a stadiometer (SECA-763 ${ }^{\mathrm{TM}}$ ). Body mass index was calculated using the following formula: Weight $(\mathrm{kg})$ divided by height $(\mathrm{m})^{2}$.

Blood pressure was measured using an electronic Omron HEM-780 automatic upper arm blood pressure monitor (Omron Healthcare), with two readings 5 min apart, and the average blood pressure was taken. Hypertension was diagnosed if the patient was previously or currently taking medications to treat hypertension and had a systolic blood pressure $\geq 140 \mathrm{mmHg}$ and/or diastolic blood pressure of $90 \mathrm{mmHg}$.

Laboratory tests. For each patient, $10 \mathrm{ml}$ venous blood was obtained in the morning (between 8:00 and 9:00 am). Subsequently, the blood samples were analyzed using a Cobas E411 Analyzer electrochemiluminescence immunoassay (Roche Diagnostics).

LH, FSH, dehydroepiandrosterone sulfate, ACTH, cortisol, TT, sex hormone-binding globulin (SHBG) and prolactin (PRL) levels were measured.

The serum albumin levels were measured using a Cobas C311 fully automated chemical analyzer (Roche Diagnostics). FT levels were calculated based on TT and SHBG levels using an online-based calculator (issam.ch/freetesto.htm).

The total cumulative GC dose for all participants currently using GCs was calculated by multiplying the duration of GC use by the equivalent GC value (Table I) and subsequently by the daily dosage [for both prednisolone and dexamethasone per Orem (PO)]. For the depot preparations, the total cumulative dose was calculated by multiplying the total received dose by the duration of use.

Statistical analysis. Statistical analysis was performed using SPSS version 23.0 (IBM, Corp.). Bivariate analysis was used to analyze continuous variables and frequencies, and percentages for the categorical variables. A $\chi^{2}$ test was used to compare categorical variables, with $95 \%$ confidence intervals. A two-tailed $\mathrm{P}$-value of $\mathrm{P}<0.05$ was considered to indicate a statistically significant difference. Receiver operating characteristic (ROC) curves were used to compare the predictive value of the different statistical values, the area under the curve (AUC) and the cutoff values, with both the sensitivity and specificity values were obtained. 
Table I. Glucocorticoid equivalent.

\begin{tabular}{|c|c|c|c|c|c|}
\hline \multirow[b]{2}{*}{ Treatments } & \multirow{2}{*}{$\begin{array}{c}\text { Equivalent } \\
\text { glucocorticoid, mg }\end{array}$} & \multicolumn{2}{|c|}{$\begin{array}{l}\text { Potency relative } \\
\text { to hydrocortisone }\end{array}$} & \multicolumn{2}{|c|}{ Half-life } \\
\hline & & Anti-inflammatory & $\mathrm{MC}$ & Plasma, min & Duration of action, $\mathrm{h}$ \\
\hline \multicolumn{6}{|l|}{ Short acting } \\
\hline Hydrocortisone & 20 & 1 & 1 & 90 & $8-12$ \\
\hline Cortef, Cortisol & 25 & 0.8 & 0.8 & 30 & $8-12$ \\
\hline \multicolumn{6}{|l|}{ Intermediate-acting } \\
\hline Prednisone & 5 & 4 & 0.8 & 60 & $12-36$ \\
\hline Prednisolone & 5 & 4 & 0.8 & 200 & $12-36$ \\
\hline Triamcinolone & 4 & 5 & 0 & 300 & $12-36$ \\
\hline Methylprednisolone & 4 & 5 & 0.5 & 180 & $12-36$ \\
\hline \multicolumn{6}{|l|}{ Long-acting } \\
\hline Dexamethasone & 0.75 & 30 & 0 & 200 & $36-54$ \\
\hline Betamethasone & 0.6 & 30 & 0 & 300 & $36-54$ \\
\hline \multicolumn{6}{|l|}{ Mineralocorticoid } \\
\hline Fludrocortisone & 0 & 15 & 150 & 240 & $24-36$ \\
\hline Aldosterone & 0 & 0 & $400+$ & 20 & - \\
\hline
\end{tabular}

Cortef, generic name for hydrocortisone.

Table II. General characteristics of the study population.

Variables

Median age, years (range)

Smoker

Yes

No

BMI, $\mathrm{kg} / \mathrm{m}^{2}$

Total Testosterone, ng/dl (range)

Free Testosterone, ng/dl

Sex hormone-binding globulin, nmol/l (range)

Follicle stimulating hormone, $\mathrm{mlU} / \mathrm{ml}$ (range)

Luteinizing hormone, $\mathrm{mlU} / \mathrm{ml}$ (range)

Prolactin, nmol/l (range)

Estradiol, pg/ml (range) $\mathrm{n}, \%$ or mean \pm standard deviation

$37(17-50)$

$107(70.40)$

45 (29.60)

$391.64 \pm 208.38(246-916)$

$8.90 \pm 5.93$

$34.42 \pm 25.47(10-60)$

$4.24 \pm 2.71(1-13)$

$5.82 \pm 3.82(1-9)$

$14.55 \pm 9.04(4-30)$

$19.11 \pm 12.57$ (range)

\section{Results}

Characteristics of the cohort. General characteristics of the entire cohort are presented in Table II. The mean age was 37 years (range 17-50), and 107 (70.40\%) individuals in the cohort were smokers. The mean BMI of all participants was $26.60 \pm 6.68 \mathrm{~kg} / \mathrm{m}^{2}$. Of the GC users, 3 (3\%) exhibited clinical features of hypogonadism, all of these were current GC users, and two of these showed stigmata of clinical hypercortisolism.

Based on the hormonal assessments, the mean TT level was $391.64 \pm 208.38 \mathrm{ng} / \mathrm{dl}$, the mean FT level was $8.90 \pm 5.93 \mathrm{ng} / \mathrm{dl}$ and the mean SHBG level was $34.42 \pm 25.47 \mathrm{nmol} / \mathrm{l}$. The mean FSH level was $4.54 \pm 3.58 \mathrm{mlU} / \mathrm{ml}$, the $\mathrm{LH}$ level was $5.82 \pm 3.82 \mathrm{mlU} / \mathrm{ml}$, the prolactin level was $14.55 \pm 9.04 \mathrm{~S}$ and the mean estradiol level was $19.11 \pm 12.57$.

Laboratory markers of the hypothalamic pituitary adrenal axis in patients using GCs were as follows: ACTH levels, $33.42 \pm 26.71 \mathrm{pg} / \mathrm{ml}$; DHEA-S levels, $129.37 \pm 123 \mu \mathrm{g} / \mathrm{dl}$; and cortisol levels, $11.90 \pm 11.23 \mu \mathrm{g} / \mathrm{dl}$.

Effect of current GC exposure. The effect of current GC use on the HPG axis is shown in Table III. There was clear and significant reduction in both the TT and FT levels $(\mathrm{P}<0.001)$. 
Table III. Effect of current glucocorticoid use on the hypothalamic-pituitary-gonadal axis.

\begin{tabular}{|c|c|c|c|}
\hline Factors & Currently using glucocorticoids ${ }^{\mathrm{b}}$ & Healthy controls ${ }^{\mathrm{b}}$ & P-value \\
\hline Total testosterone, ng/dl & $318.08 \pm 209.61$ & $430.40 \pm 166.59$ & $<0.001^{\mathrm{a}}$ \\
\hline Free testosterone, ng/dl & $7.05 \pm 4.09$ & $9.97 \pm 5.49$ & $<0.001^{\mathrm{a}}$ \\
\hline Sex hormone-binding globulin, nmol/l & $32.11 \pm 27.47$ & $35.55 \pm 27.35$ & 0.492 \\
\hline Follicle stimulating hormone, $\mathrm{mlU} / \mathrm{ml}$ & $4.24 \pm 2.74$ & $3.98 \pm 2.19$ & 0.569 \\
\hline Luteinizing hormone, $\mathrm{mlU} / \mathrm{ml}$ & $5.64 \pm 4.99$ & $5.88 \pm 3.12$ & 0.745 \\
\hline Prolactin, $\mathrm{ng} / \mathrm{ml}$ & $15.47 \pm 11.06$ & $14.14 \pm 8.16$ & 0.509 \\
\hline Estradiol, pg/ml & $19.83 \pm 13.54$ & $16.22 \pm 12.66$ & 0.185 \\
\hline
\end{tabular}

${ }^{\mathrm{a}} \mathrm{P}<0.001 .{ }^{\mathrm{b}}$ Mean \pm standard deviation.

Table IV. Effect of discontinuation of glucocorticoid use on the hypothalamic-pituitary-gonadal axis.

\begin{tabular}{|c|c|c|c|}
\hline Factors & Previous glucocorticoid use ${ }^{b}$ & Healthy controls ${ }^{\mathrm{b}}$ & P-value \\
\hline Total testosterone, ng/dl & $489.81 \pm 236.22$ & $430.40 \pm 166.59$ & 0.119 \\
\hline Free testosterone, ng/dl & $10.08 \pm 6.26$ & $9.97 \pm 5.49$ & 0.926 \\
\hline Sex hormone-binding globulin, nmol/l & $39.37 \pm 22.30$ & $35.55 \pm 27.35$ & 0.449 \\
\hline Follicle stimulating hormone, $\mathrm{mlU} / \mathrm{ml}$ & $3.68 \pm 2.31$ & $3.98 \pm 2.19$ & 0.498 \\
\hline Luteinizing hormone, $\mathrm{mlU} / \mathrm{ml}$ & $5.68 \pm 2.97$ & $5.88 \pm 3.12$ & 0.743 \\
\hline Prolactin, ng/ml & $15.13 \pm 7.70$ & $14.14 \pm 8.16$ & 0.567 \\
\hline Estradiol, pg/ml & $22.33 \pm 10.70$ & $16.22 \pm 12.66$ & $0.022^{\mathrm{a}}$ \\
\hline
\end{tabular}

${ }^{\mathrm{a}} \mathrm{P}<0.05 .{ }^{\mathrm{b}} \mathrm{Mean} \pm$ standard deviation.

Current GC use had no significant effect on the SHBG, FSH, LH, PRL and estradiol (E2) levels.

Effect of previous GC use. The effects of discontinuing GCs on the HPG axis is shown in Table IV. There was a significant increase in $\mathrm{E} 2$ level $(\mathrm{P}=0.022)$ in patients who previously used GCs compared with healthy patients, whereas the levels of all hormones did not differ significantly between the healthy controls and patients who previously used GCs.

Patients who were previously using GCs had a mean E2 level of $22.33 \pm 10.70 \mathrm{pg} / \mathrm{ml}$, whereas patients who were currently using GCs had a mean E2 level of $19.83 \pm 13.54 \mathrm{pg} / \mathrm{ml}$, and this difference was significant. The subgroup analysis of these different GC formulations showed that only prednisolone PO (tablets), dexamethasone PO, and betamethasone acetate injections were statistically significantly associated with hypogonadism ( $\mathrm{P}=0.018,0.009$ and 0.002 , respectively).

The area under the curve (AUC) based on the receiver operating characteristics (ROC) demonstrated that there was a 3.7-fold increase in the risk of hypogonadism in patients who used a total cumulative equivalent dose of $>240 \mathrm{mg}$, and this increased risk was most likely due to GC use, with a specificity of $81 \%$ and a sensitivity of $50 \%(\mathrm{P}=0.038$; Fig. $1 \mathrm{~A})$.

Comparison between current GC use and no previous use. Regarding the 31 patients using dexamethasone PO, the risk of hypogonadism was 7.5-fold if they were taking a total
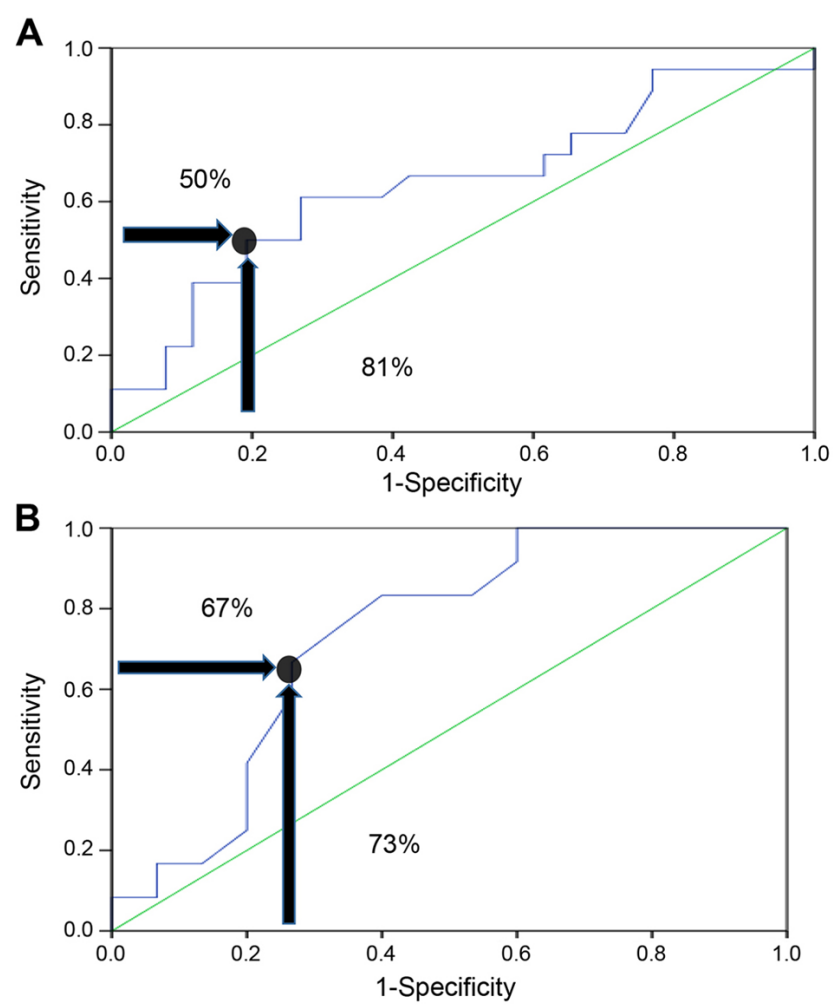

Figure 1. Receiver operating curves. (A) Receiver operating characteristic curve of the effect of a cumulative dose of $240 \mathrm{mg}$ glucocorticoids on hypogonadism. (B) Receiver operating characteristic curve of the cumulative dose of dexamethasone on hypogonadism. 
Table V. Frequency of hypogonadism among patients currently using glucocorticoids compared with individuals who had never used glucocorticoids.

\begin{tabular}{|c|c|c|c|c|c|}
\hline \multirow[b]{2}{*}{ Treatments } & \multicolumn{2}{|c|}{ Hypogonadism, n (\%) } & \multirow[b]{2}{*}{ Odds ratio } & \multirow[b]{2}{*}{ Confidence interval } & \multirow[b]{2}{*}{ P-value } \\
\hline & Yes & No & & & \\
\hline Glucocorticoid & & & 4.34 & $1.67-11.31$ & $<0.001^{\mathrm{c}}$ \\
\hline User & $23(40.4)$ & 34 (59.6) & & & \\
\hline Not user & $7(13.5)$ & $45(86.5)$ & & & \\
\hline Prednisolone PO & & & 8.57 & $1.57-46.71$ & $0.018^{\mathrm{a}}$ \\
\hline User & $4(57.1)$ & $3(42.9)$ & & & \\
\hline Not user & $7(13.5)$ & $45(86.5)$ & & & \\
\hline Dexamethasone PO & & & 2.87 & $1.26-6.52$ & $0.009^{b}$ \\
\hline User & $12(38.7)$ & $19(61.3)$ & & & \\
\hline Not user & $7(13.5)$ & $45(86.5)$ & & & \\
\hline Dexamethasone PO, Cumulative dose & & & 7.5 & $1.46-38.28$ & $0.015^{\mathrm{a}}$ \\
\hline$\geq 18.9 \mathrm{mg}$ & $8(66.7)$ & $4(33.3)$ & & & \\
\hline$<18.9 \mathrm{mg}$ & $4(21.1)$ & $15(78.9)$ & & & \\
\hline Dexamethasone injection & & & 1.85 & $0.29-11.6$ & 0.47 \\
\hline User & $1(25)$ & $3(75)$ & & & \\
\hline Not user & $7(13.5)$ & $45(86.5)$ & & & \\
\hline Methylprednisolone acetate injection & & & 3.3 & $1.2-9.01$ & $0.047^{\mathrm{a}}$ \\
\hline User & $4(44.4)$ & $5(55.6)$ & & & \\
\hline Not user & $7(13.5)$ & 45 (86.5) & & & \\
\hline Betamethasone acetate injection & & & 4.33 & $1.87-10.02$ & $0.002^{\mathrm{b}}$ \\
\hline User & $7(58.3)$ & $5(41.7)$ & & & \\
\hline Not user & $7(13.5)$ & $45(86.5)$ & & & \\
\hline Total cumulative equivalent dose & & & 3.72 & $1.05-13.22$ & $0.038^{\mathrm{a}}$ \\
\hline$\geq 240 \mathrm{mg}$ & $9(64.3)$ & $5(35.7)$ & & & \\
\hline$<240 \mathrm{mg}$ & $14(32.6)$ & $29(67.4)$ & & & \\
\hline
\end{tabular}

${ }^{\mathrm{a}} \mathrm{P}<0.05,{ }^{\mathrm{b}} \mathrm{P}<0.01,{ }^{\mathrm{c}} \mathrm{P}<0.001$. $\mathrm{PO}$, per Orem.

dexamethasone cumulative dose of $>18.9 \mathrm{mg}$, with a sensitivity and a specificity of 67 and $73 \%$, respectively $(\mathrm{P}=0.015$; Fig. 1B). Oral dexamethasone can cause hypogonadism at lower total cumulative equivalent doses. A ROC curve was not plotted for patients who were currently using GCs (prednisolone, dexamethasone injections, methylprednisolone acetate, and betamethasone acetate) due to the smaller numbers of patients who were currently using each type of these GCs.

The formulations of dexamethasone injection and methylprednisolone acetate were not statistically associated with hypogonadism (Table V).

Comparison between current GC use and previous GC use. There was a significant association between the current use of GCs and the state of hypogonadism (23 patients; 40\%) compared with those who previously used GCs, (3 patients; $7 \%$; $\mathrm{P}<0.0001)$. This association was primarily due to use of oral dexamethasone use in (12 patients; 39\%).

Table VI shows the effects of previous GC use on the HPG axis compared with patients who currently use GCs. The mean TT level was $318.08 \pm 209.61 \mathrm{ng} / \mathrm{dl}$ in patients currently using
GCs and 489.81 $\pm 236.22 \mathrm{ng} / \mathrm{dl}$ in patients who previously used GCs, and this difference was significant $(\mathrm{P}<0.0001)$. The mean FT level was $10.08 \pm 6.26 \mathrm{ng} / \mathrm{dl}$ for previous GC users, and $7.05 \pm 4.09 \mathrm{ng} / \mathrm{dl}$ in current $\mathrm{GC}$ users $(\mathrm{P}=0.004)$.

\section{Discussion}

In the present study, in patients currently using GC, hypogonadism manifested as low TT levels in $<50 \%$ of the study sample. These results are comparable to a cross-sectional study by Morrison et al (17) in 1994 at the University of Wales, who studied 61 male patients with chronic respiratory diseases, 12 of whom were long-term users of systemic GCs, $31 \%$ of which had low TT levels.

Furthermore, TT and FT levels in patients currently using GC with different formulations were significantly decreased, similar to a cross-sectional study by Contreras et al (18) in 1996 at Jose de San Martin Hospital, which included 17 patients with bronchial asthma and uveitis on long-acting GCs (methylprednisolone acetate injections). This significant reduction in FT levels was also consistent with the results 
Table VI. Frequency of hypogonadism among patients currently using glucocorticoids compared with patients who had previously used glucocorticoids.

\begin{tabular}{|c|c|c|c|c|c|}
\hline \multirow[b]{2}{*}{ Treatments } & \multicolumn{2}{|c|}{ Hypogonadism, n (\%) } & \multirow[b]{2}{*}{ Odds ratio } & \multirow[b]{2}{*}{ Confidence interval } & \multirow[b]{2}{*}{ P-value } \\
\hline & Yes, $n=26$ & No, $n=74$ & & & \\
\hline Glucocorticoid & & & 0.11 & $0.03-04$ & $<0.0001^{\mathrm{a}}$ \\
\hline Current user & $23(40.40)$ & $34(59.60)$ & & & \\
\hline Previous user & $3(7.00)$ & $40(93.00)$ & & & \\
\hline Prednisolone PO & & & 0.12 & $0.01-1.67$ & 0.133 \\
\hline Current user & $4(57.10)$ & $3(42.90)$ & & & \\
\hline Previous user & $1(14.30)$ & $6(85.70)$ & & & \\
\hline Dexamethasone PO & & & 0.05 & $0.01-0.42$ & $<0.0001^{\mathrm{a}}$ \\
\hline Current user & $12(38.70)$ & $19(61.30)$ & & & \\
\hline Previous user & $1(3.10)$ & $31(96.90)$ & & & \\
\hline Dexamethasone injection & & & 1.33 & $0.75-2.34$ & 0.444 \\
\hline Current user & $1(25.00)$ & $3(75.00)$ & & & \\
\hline Previous user & $0(0.00)$ & $5(100.00)$ & & & \\
\hline Methylprednisolone acetate injection & & & 0.45 & $1.29-1.56$ & 0.208 \\
\hline Current user & $4(44.40)$ & $5(55.60)$ & & & \\
\hline Previous user & $3(20.00)$ & $12(80.00)$ & & & \\
\hline Betamethasone acetate injection & & & 2.40 & $1.22-4.68$ & 0.069 \\
\hline Current user & $7(58.30)$ & $5(41.70)$ & & & \\
\hline Previous user & $0(0.00)$ & $4(100.00)$ & & & \\
\hline
\end{tabular}

${ }^{\mathrm{a}} \mathrm{P}<0.001 . \mathrm{PO}$, per Orem.

of a case-controlled study conducted in Karolinska Institute at Huddinge University Hospital in 2002, which enrolled 104 patients with Rheumatoid Arthritis (RA) who received oral prednisolone and other disease-modifying antirheumatic drugs (19).

One of the significant findings in the present study was the increase in E2 levels in patients with a history of previous GC use, whilst the other HPG axis functions were normal. The mechanism underlying the increased E2 levels in patients who previously used GC is unclear, but may be associated with the activation of the aromatase enzyme after the TT levels return to normal; as proposed by a retrospective multicenter study by Tan et al (20) between 2009-2014, which evaluated the electronic health records and medical chart review of 34,016 patients in 35 geographically diverse cities in the USA. Other explanations for the increased E2 levels are possibly attributed to the severe loss of libido and hypogonadism (21), or to the antagonistic effect of GC on estrogen (22).

The TT and FT levels returned to their normal reference ranges in patients who previously used GC compared with those currently using GC. This is likely due to the recovery of the HPG axis following drug withdrawal, consolidating the idea of causality of low TT levels in GC users.

There was a 4-fold increased risk of hypogonadism (low TT levels) in patients currently using GC compared with GC-naive patients. A similar study assessing the risk of causality of hypogonadism in patients using GCs has not been performed, to the best of our knowledge.
Regarding hypogonadism, according to the type of GC administered/used, $>50 \%$ of the patients on oral prednisolone developed hypogonadism compared with those who were not using GCs. Morrison et al (17) showed that TT levels decreased to $33 \%$ in patients who used prednisolone.

Regarding other types of GC, in the present study, it was observed that oral dexamethasone resulted in less hypogonadism compared with injectable betamethasone and the control group who never used GCs, warranting further studies on the differences of different GC formulations in hypogonadism.

An extensive study assessing the effects of different types of GC on the HPG axis similar to our study has not been conducted yet, to the best of our knowledge. Most studies use one or two types of GC only such as the case-control study by MacAdams et al (9) in 1986, in which oral prednisolone or methylprednisolone acetate injections were used by the patients. A clinical trial conducted by Martens et al (23) in August 1994 in Seattle, USA, studied the effect of long-standing low-dose oral prednisolone on 36 men with RA compared with 71 aged-matched control men with RA not taking prednisolone, and found partial gonadal failure caused by the decrease in TT levels and slight increase in FSH and LH levels in the patients taking prednisolone compared with the control group, in which there was marked increase in FSH and LH levels with normal TT level.

Compared with the 240-mg total cumulative equivalent cutoff dose of prednisolone in the present study causing hypogonadism, the effects of GCs on gonadal function were confirmed by Morrison et al (17), in which patients using long-term oral 
prednisolone (5-20 mg daily), high-dose inhaled beclomethasone dipropionate (1,500-2,250 $\mu \mathrm{g}$ daily) or low-dose beclomethasone inhaler (200-800 $\mu \mathrm{g}$ daily). They compared all groups with 19 patients not receiving GCs, and found that the TT levels among these patients taking GCs were decreased by $31 \%$.

Contreras et al (18) studied gonadal function in 17 patients with bronchial asthma and uveitis who were treated with methylprednisolone acetate injections. The patients were administered $10 \mathrm{mg}$ methylprednisolone daily with a total cumulative dose ranging between 1,200-45,500 $\mathrm{mg}$. The mean cumulative dose was $4,080 \pm 367 \mathrm{mg}$, which resulted in a decrease in TT levels (18).

In MacAdams et al (9) were mainly dependent on the duration of GC use regardless of the dose and route of administration (either prednisolone tablets or methylprednisolone acetate injections), and there was no significant difference between each group (daily or alternative daily use) in the reduction of TT levels. Arnaud et al (7) studied the effects of oral prednisolone use, but did not assess the effects of dose or duration of prednisolone use.

Oral dexamethasone use results in hypogonadism at lower total cumulative doses when compared with other types of GC, and this may be associated with the longer half-life of dexamethasone, reaching up to 3 days, compared with other GC types (24) or associated with the potency of dexamethasone (25).

Hypogonadism affected half of study sample using GCs, and may be reversible. Based on the results of the present study, there was marked hypogonadism in patients currently using GC with a total cumulative dose of $240 \mathrm{mg}$ (equivalent to prednisolone as shown in Table I) with no feedback effect on LH and FSH levels. Oral dexamethasone caused hypogonadism at a lower total cumulative dose.

An increase in E2 levels was observed in patients previously using GCs, whilst all the other gonadal hormones, and in particular TT, were within the normal ranges.

The present study has some limitations. Firstly, the present study was a cross-sectional case-controlled study, with limited external validity, and thus the observations are not generalizable. The present study was performed using a relatively homogenous high-risk population, and as with all observational data analyses, it was not possible to establish causality from an association. Additionally, the sample size was small, and a single-center study. Finally, due to the short duration of the study, it was not possible to follow up the patients for assessment of future complications.

A prospective longitudinal study is required to evaluate patients who withdraw the use of GCs to assess the reversibility and the temporal relation of the recovery of the HPG axis.

An awareness campaign is required to reduce the use of GCs among the general population, which are considered as dangerous drugs with several side effects, including hypogonadism as a serious complication.

If GCs are prescribed for any condition, it should be advised to avoid oral dexamethasone as it may result in hypogonadism with even low doses compared with other types of GC.

\section{Acknowledgements}

The authors would like to thank Dr Nassar Taha Yassin, Dr Haider Ayad and Mr Ali Hamza (FDEMC) for providing medical writing support.

\section{Funding}

No funding was received.

\section{Availability of data and materials}

The datasets used and/or analyzed during the present study are available from the corresponding author on reasonable request.

\section{Authors' contributions}

AGM and JHA were responsible for the preparation and drafting of the Introduction and Discussion. AGM and AAM were responsible for the preparation and drafting of the Materials and methods. AGM performed the statistical analysis and was responsible for the preparation and drafting of the Results and the final manuscript. AGM, AAM and JHA critically revised the manuscript for important intellectual content. All authors have read and approved the final manuscript.

\section{Ethics approval and consent to participate}

The present study was approved by the Faiha Specialized Diabetes, Endocrine and Metabolism Center (Basrah, Iraq). Each participant provided written informed consent.

\section{Patient consent for publication}

Not applicable.

\section{Competing interests}

The authors declare that they have no competing interests.

\section{References}

1. Pantalone KM and Faiman C: Male hypogonadism: More than just a low testosterone. Cleve Clin J Med 79: 717-725, 2012.

2. Wang C and Swerdloff R: Definition of male hypogonadism. 2011.

3. Melman A and Gingell JC: The epidemiology and pathophysiology of erectile dysfunction. J Urol 161: 5-11, 1999.

4. Hijazi RA and Cunningham GR: Andropause: Is androgen replacement therapy indicated for the aging male? Annu Rev Med 56: 117-137, 2005.

5. Bhasin S, Cunningham GR, Hayes FJ, Matsumoto AM, Snyder PJ, Swerdloff RS and Montori VM: Testosterone therapy in adult men with androgen deficiency syndromes: An endocrine society clinical practice guideline. J Clin Endocrinol Metab 91: 1995-2010, 2006.

6. Rey RA, Grinspon R, Gottlieb S, Pasqualini T, Knoblovits P, Aszpis S, Pacenza N, Stewart Usher J, Bergadá I and Campo SM: Male hypogonadism: An extended classification based on a developmental, endocrine physiology-based approach. Andrology 1: 3-16, 2013 .

7. Arnaud L, Nordin A, Lundholm H, Svenungsson E, Hellbacher E, Wikner J, Zickert A and Gunnarsson I: Effect of corticosteroids and cyclophosphamide on sex hormone profiles in male patients with systemic lupus erythematosus or systemic sclerosis. Arthritis Rheumatol 69: 1272-1279, 2017.

8. Mager DE, Lin SX, Blum RA, Lates CD and Jusko WJ: Dose equivalency evaluation of major corticosteroids: Pharmacokinetics and cell trafficking and cortisol dynamics. J Clin Pharmacol 43: 1216-1227, 2003.

9. MacAdams MR, White RH and Chipps BE: Reduction of serum testosterone levels during chronic glucocorticoid therapy. Ann Intern Med 104: 648-651, 1986. 
10. Moghadam-Kia S and Werth VP: Prevention and treatment of systemic glucocorticoid side effects. Int J Dermatol 49: 239-248, 2010.

11. Whirledge S and Cidlowski JA: Glucocorticoids, stress, and fertility. Minerva Endocrinol 35: 109-125, 2010.

12. Yazawa H, Sasagawa I and Nakada T: Apoptosis of testicular germ cells induced by exogenous glucocorticoid in rats. Hum Reprod 15: 1917-1920, 2000.

13. Crawford BA, Liu PY, Kean MT, Bleasel JF and Handelsman DJ: Randomized placebo-controlled trial of androgen effects on muscle and bone in men requiring long-term systemic glucocorticoid treatment. J Clin Endocrinol Metab 88: 3167-3176, 2003.

14. Costello R, Patel R, Humphreys J, McBeth J and Dixon WG: Timing of glucocorticoid administration: A cross-sectional survey of glucocorticoid users in an online social network for health. Rheumatology (Oxford, England) 56: 494-495, 2017.

15. Woolf PD, Hamill RW, Mcdonald JV, Lee LA and Kelly M: Transient hypogonadotropic hypogonadism caused by critical illness. J Clin Endocrinol Metab 60: 444-450, 1985.

16. Woolf P, Hamill R, McDonald J, Lee LA and Kelly M: Transient hypogonadotrophic hypogonadism after head trauma: Effects on steroid precursors and correlation with sympathetic nervous system activity. Clin Endocrinol (Oxf) 25: 265-274, 1986.

17. Morrison D, Capewell S, Reynolds S, Thomas J, Ali N, Read G, Henley R and Riad-Fahmy D: Testosterone levels during systemic and inhaled corticosteroid therapy. Respir Med 88: 659-663, 1994

18. Contreras LN, Masini AM, Danna MM, Kral M, Bruno OD, Rossi MA and Andrada JA: Glucocorticoids: Their role on gonadal function and LH secretion. Minerva Endocrinol 43-46, 1996.
19. Tengstrand $\mathrm{B}$, Carlström $\mathrm{K}$ and Hafström I: Bioavailable testosterone in men with rheumatoid arthritis-high frequency of hypogonadism. Rheumatology (Oxford) 41: 285-289, 2002.

20. Tan RS, Cook KR and Reilly WG: High estrogen in men after injectable testosterone therapy: The low $\mathrm{T}$ experience. Am J Mens Health 9: 229-234, 2015.

21. Lee JK and Imperato-McGinley J: Estrogen and the male. 2004.

22. Gong H, Jarzynka MJ, Cole TJ, Lee JH, Wada T, Zhang B, Gao J, Song WC, DeFranco DB, Cheng SY and Xie W: Glucocorticoids antagonize estrogens by glucocorticoid receptor-mediated activation of estrogen sulfotransferase. Cancer Res 68: 7386-7393, 2008.

23. Martens H, Sheets P, Tenover J, Dugowson C, Bremner W and Starkebaum G: Decreased testosterone levels in men with rheumatoid arthritis: Effect of low dose prednisone therapy. J Rheumatol 21: 1427-1431, 1994.

24. He Y, Yi W, Suino-Powell K, Zhou XE, Tolbert WD, Tang X, Yang J, Yang H, Shi J, Hou L, et al: Structures and mechanism for the design of highly potent glucocorticoids. Cell Res 24: 713-726, 2014.

25. Steven K: Adrenal cortical steroids. Drug facts and comparisons 5th ed St Louis: Facts and Comparisons, Inc. pp.122-128, 1997.

This work is licensed under a Creative Commons Attribution-NonCommercial-NoDerivatives 4.0 International (CC BY-NC-ND 4.0) License. 